\title{
Pentingnya Intuisi Dalam Dimensi Hidup Yang Tidak Terbatas
}

\author{
Erin Eflin Linggi Allo
}

\begin{abstract}
Someone who has high intuition must have wisdom in making decisions. This journal does not focus on just one dimension but covers the entire community in society. The community is formed because of a sense of unity and brotherhood among members who interact with each other. In everyday life, social communities can be found in the surrounding environment that arises not only because of a sense of unity, but also because of the same goals, needs, and resources. This journal is the development of Rannu Sanderan's journal, namely "The Deepening of Hans-George Gadamer's Ideas on Intuition as Supralogic". So this journal will discuss the concept of Gadamer. To realize intuition, let's be a person who is not limited by one dimension.
\end{abstract}

Keywords: intuition, truth, dimension, supralogical, truth

\begin{abstract}
Abstrak
Seseorang yang memiliki intuisi tinggi pasti memiliki kebijaksanaan dalam pengambilan keputusan. Jurnal ini tidak berfokus pada satu dimensi saja tetapi mencakup seluruh komunitas dalam masyarakat. Komunitas terbentuk kerena adanya rasa persatuan dan persaudaraan di antara anggota yang saling berinteraksi. Dalam kehidupan sehari-hari, komunitas sosial bisa ditemui di lingkungan sekitar yang muncul bukan hanya karena rasa persatuan, melainkan adanya tujuan, kebutuhan, sumber daya yang sama. Jurnal ini ialah pengembangan jurnal dari Rannu Sanderan yaitu "Pendalaman Gagasan Hans-George Gadamer tentang Intuisi sebagai Supralogika”. Jadi jurnal ini akan membahas konsep dari Gadamer. Untuk mewujudkan intuisi mari menjadi pribadi yang tidak dibatasi oleh satu dimensi saja.
\end{abstract}

Kata Kunci: intuisi, kebenaran, dimensi, supralogika, kebenaran

\section{Pendahuluan}

Kita ditetapkan oleh Tuhan untuk menjadi berkat bukan hanya bagi saudara seiman atau gereja, melainkan juga bagi bangsa dan negara bahkan dalam dunia ini. Janji Tuhan yang 
telah menetapkan kita menjadi kepala dan bukan ekor di dunia ini? Kapan dan bagaimana mewujudkannya? Untuk mewujudkannya, kita harus bergerak dalam panggilan tersebut sejak dini dan saat ini. Setiap kita hendaknya mulai bergerak dalam keberanian, semangat, keyakinan, dan kekuatan penuh; selain itu, kita tidak boleh lagi perpikir picik dengan hanya hidup memikirkan diri sendiri, komunitas sendiri, bahkan gereja sendiri! Sudah saatnya kita membuka mata melihat kondisi kota, bangsa, bahkan dunia. Kita bergerak di dalamnya menjadi kepala dan bukan ekor, dengan memberikan pengaruh dan bukan di pengaruhi, sehingga kita bisa menjadi berkat bagi banyak orang termasuk dalam komunitas.

Pengungkapan intuisi dalam diri individu maupun dalam interaksinya diejawantahkan dalam realita dan reaksi "kebetulan", yang sejatinya segenap kehidupan secara "ontis" adalah kebetulan. ${ }^{1}$ Banyak orang beranggapan bahwa intuisi adalah suatu hal kebetulan. Akan tetapi, ada beberapa individu yang intuisinya jarang gagal, bahkan selalu menjadi kenyataan. Kalau begitu, sudah pasti hal ini bukanlah hanya sebuah kebetulan. Gadamer sendiri pada dasarnya memiliki proses penafsiran metodik yang disebut lingkaran hermeneutis ${ }^{2}$. Istilah hermeneutis disebut sebagai lingkaran pemahaman, dikaitkan dengan masalah sentral humaniora, teori sains yang berorientasi ilmiah, penjelasan tentang cara pemahaman yang lebih tinggi muncul dari konten pemahaman dasar karena dengan keterkaitan antara Utuh dan bagian individu dari apa yang harus dipahami.

\section{Tujuan dan Manfaat}

Tujuan

Sebenanya tidak ada yang salah dengan intuisi, karena nyatanya setiap manusia memiliki hal tersebut. Namum hanya cara mengolah intuisi tersebutlah yang menjadikan seseorang memiliki kemampuan tententu. Pada tingkatan yang lebih tinggi justru intuisi dapat menjadi tujuan dalam hidup. Semuanya berujung pada pengertian kesuksesan yang diinginkan oleh setiap orang.

Manfaat

\footnotetext{
${ }^{1}$ Rannu Sanderan, "Pendalaman Gagasan Hans-George Gadamer tentang Intuisi sebagai Supralogika” Jurnal Ilmiah Religiosity Entity Humanity (JIREH) 2, no.2(Desember 2020): 115 http://ojsjireh.org/index.php/iireh/article/view/39

2 Ibid: 116, 115 http://ojs-jireh.org/index.php/jireh/article/view/39
} 
Intuisi sering dikatakan sebagai bimbingan batin, yang dijelaskan sebagai suatu mekanisme batin atau mengetahui secara naluriah tanpa membutuhkan proses berpikir logis. Intuisi disebut alternatif sumber pengetahuan, tingkat kesadaran, atau sebagian orang menyebutnya, suara batin. Semua orang tentu memiliki mekanisme ini dengan berbagai tingkatan serta kemampuan untuk mengembangkan intuasi lebih lanjut.

\section{Pembahasan}

Pikiran seseorang sesungguhnya memiliki kemampuan yang tidak terbatas. Pikiran biasanya memikirkan apa yang tidak ada menjadi ada; seperti berimajinasi, berencana, dan dapat bergerak ke masa lalu dan ke masa depan. Kemampuan berpikir seseorang sangat menentukan pribadi dan hidup seseorang. Sebab, sesungguhnya hidup ini ditentukan oleh pikiran karena apa yang kita lakukan pada umumnya lahir dari pikiran. Jika kita menginginkan pribadi yang tidak terbatas, pikiran kita mau tidak mau harus tidak terbatas pula agar tindakan dan pengaruh kita tidak terbatas. Artinya, pikiran duniawi yang egois, pesimis, dan negatif, harus diterobos dan ditinggalkan jauh-jauh dan digantikan dengan pikiran yang optimis, positif, dan biblical minded.

Seorang mahasiswa yang memiliki motivasi intrinsik biasanya akan menghasilkan kualitas pendidikan yang tinggi, menyelesaikan tugas dari dosen tepat waktu, dan mampu berorganisasi dengan baik. Hal ini terjadi karena adanya dorongan dari dalam diri mahasiswa tersebut untuk mengukur batas kemampuannya untuk mencapai suatu target yang ia tetapkan dalam dirinya. Motivasi intrinsik sangat dibutuhkan sebab sifatnya murni dan bertahan lama; motivasi intrinsik akan semakin berpengaruh jika ditopang dengan adanya motivasi da ri luar (teladan) $)^{3}$.

Kita adalah tuan atas pikiran kita. Jadi, kitalah yang harus mengendalikannya dan mengisinya dengan hal-hal yang benar, agar menghasilkan hal-hal yang benar pula. Hal sederhana untuk mengembangkan pikiran yang tidak terbatas adalah dengan terus-menerus menjadi manusia pembelajar yang memiliki kerinduan dan kehausan untuk mempelajari firman Tuhan (pertama dan utama) dan pengetahuan lain yang bermanfaat!. Orang yang berhenti belajar sesungguhnya telah berhenti hidup!. Mengapa? Karena dengan berhenti belajar ia sedang membatasi pikiran/pengetahuan/wawasan/pandangannya sehingga akhirnya ia hidup dalam kepicikan yang membentuk dirinya untuk menutup diri sendiri dalam

\footnotetext{
${ }^{3}$ Rannu Sanderan, “Exemplary Menemukan Kunci Pendidikan Iman Bagi Anak Dalam Keluarga dan Pembelajaran agama di Sekolah" (2021), https://osf.io/bmtrk/
} 
berkembang, bertumbuh yang akhirnya menghambat dirinya sendiri mengalami keberhasilan dan kemaksimalan. Hakikatnya, manusia mempunyai harga diri, harkat dan martabat pemberian Tuhan; oleh karena itu, tidak seorang pun manusia dapat menguranginya apalagi memanipulasinya ${ }^{4}$

Manusia dikenal sebagai makhluk sosial yang tidak bisa hidup seorang diri saja. Hubungan manusia dengan Tuhan berada pada dimensi spiritual yang harus dijaga melalui ibadah, doa, perenungan firman, pujian, dan penyembahan. Hubungan ini haruslah menjadi prioritas utama dalam kehidupan orang percaya (Mat. 6:33). Melalui hubungan dengan Tuhan, setiap manusia akan mengenal Tuhan, sesama, dan dirinya sendiri dengan baik. Sehingga melalui pengenalan ini, manusia menjadi tahu bagaimana berhubungan dengan Tuhan, sesama, dan diri sendiri dengan benar sesuai dengan kehendak Tuhan Sang Pencipta yang terdapat dalam Alkitab yang adalah firman Allah. Semakin baik pengenalan kita akan Tuhan sesungguhnya semakin baik pula pengenalan kita akan sesama dan diri sendiri. Arah dan tekanan bagian ini akan mencoba mengemukakan bagaimana memahami realitas umat Allah dalam kaitannya dengan masalah-masalah sosiologi secara khusus relasi antara umat Allah dalam status sosial yang berbeda ${ }^{5}$

Hubungan manusia dengan sesama manusia berada pada dimensi sosial dalam kehidupan sehari-hari. Hubungan dengan sesama adalah salah satu faktor yang menentukan kesuksesan seseorang dalam dunia ini. Semakin baik kita hubungan dengan orang lain, semakin besar peluang kesuksesan untuk kita miliki. Seperti para pembisnis, bukankah keberhasilan seorang bisnis terletak pada hubungan? Perhatikan juga usaha lainnya, seperti restoran, bengkel, salon, bahkan gereja, organisasi, komunitas! Bukankah konsumen, masyarakat, dan jemaat sangat senang bila mereka memiliki hubungan yang baik dengan pemiliknya, pelayannya, pendetanya, selain produk jasa/barang yang dihasilkan dan ditawarkan? Mengapa jaringan sosial begitu digandrungi hari-hari ini seperti Facebook, Intagram, Youtube, WhatsApp, Twitter, dll? Bahkan beberapa kepala negara, tokoh politik di dunia pun memiliki akuntersebut!. Bukankah jaringan ini semata-mata menghubungkan seseorang dengan semua orang sekalipun berada dalam jarak yang sangat jauh? Ingat! kemampuan mengelola hubungan dengan orang lain akan membuka kesempatan-kesempatan

\footnotetext{
${ }^{4}$ Rannu Sanderan, “Jabatan Gerejawi dan Peran Perempuan dalam Pelayanan Gereja”, http://osf.io/itcag

${ }^{5}$ Rannu Sanderan,"Stratifikasi Sosial Kepemimpinan Tradisional dalam Dinamika Demokrasi Modern", https://osf.io/63yai/
} 
baru untuk mengalami kesuksesan dalam pekerjaan, pelayanan, usaha, dan dalam mewujudkan panggilan Allah, yaitu menjadi berkat bagi semua bangsa di dunia.

Untuk menilai konsep Gadamer tentang memahami sebagai kesepahaman, maka kita perlu berangkat dari istilahnya yang disebut hodizon pemahaman ${ }^{6}$. Pemahaman yang efektif bukanlah pemahaman yang berdiri sendiri, justru pemahaman yang valid adalah pemahaman yang bersumber dan ditopang dari horizon-horizon yang beragam. Semakin luas horizon, semakin luas pula pemahamannya. Contohnya dalam teks Pemahaman Tantang Sayap Dalam Kitab Rut: Studi Kritik Naratif. Teks ini membutuhkan perluasan hirizon agar dapat dimengerti dengan baik, dengan kata lain seyogianya pembaca memahami kisah ini dengan melihat ayat-ayat yang medahuluinya dan ayat-ayat yang mengikutinya ${ }^{7}$

\section{Kesimpulan dan saran}

Kesimpulan

Intuisi ialah sebuah pola alternatif yang membuat seseorang mengkritik setiap situasi secara berbeda. Intuisi ini merupakan jalan pemecahan masalah dari hidup yang terpola. Kelebihan dari intuisi, memampukan seseorang untuk memaksa dirinya untuk terus menerus mengembangkan kriativitas yang dimiliki. Intuisi pun menjadi salah satu anugerah yang Allah berikan kepada umat manusia, ketika dimanfaatkan secara maksimal maka bisa menjadi sebuah senjata yang dapat diandalkan dalam menentukan tujuan demensi hidup yang tidak terbatas.

\section{Saran}

Penyusun menyadari bahwa paper ini masih jauh dari sempurna, baik dari bentuk penyusunan maupun pembahasan. Penyusun mengharapkan saran dan kritik dari para pembaca untuk penyempurnaan karya tulis selanjutnya.

\footnotetext{
${ }^{6}$ Rannu Sanderan, “Pendalaman Gagasan Hans-George Gadamer tentang Intuisi sebagai Supralogika” Jurnal Ilmiah Religiosity Entity Humanity (JIREH) 2, no.2(Desember 2020): 123, http://ojsjireh.org/index.php/iireh/article/view/39

${ }^{7}$ Rannu Sanderan, Yohanes Krismantyo Susanta, “Pemahaman Tantang Sayap Dalam Kitab Rut: Studi Kristik Naratif", Jurnal Teologi Kristen 2, no.1 (Juni 2021):52, http://kamasean.iakntoraja.ac.id/index.php/ojsdatakamasean/article/view/33
} 


\section{Daftar Pustaka}

Sanderan, Rannu. "Pendalaman Gagasan Hans-George Gadamer tentang Intuisi sebagai Supralogika” Jurnal Ilmiah Religiosity Entity Humanity (JIREH) 2, no.2(Desember 2020)

Senderan, Rannu. "Menemukan Kunci Pendidikan Iman Bagi Anak Dalam Keluarga dan Pembelajaran agama di Sekolah" (2021)," Exemplary, no.1 (2021)

Sanderan, Rannu. "Jabatan Gereja dan Peran Perempuan dalam Pelayanan Gereja".

Senderan, Rannu. "Stratifikasi Sosial Kepemimpinan Tradisional dalam Dinamika Demokrasi Modern"

Rannu Sanderan, Yohanes Krismantyo Susanta, "Pemahaman Tantang Sayap Dalam Kitab Rut: Studi Kristik Naratif”, Jurnal Teologi Kristen 2, no.1 (Juni 2021) 